\title{
The Employment Maximizing Import Quota Under Domestic Monopoly*
}

\author{
William H. Kaempfer** \\ Edward Tower*** \\ Thomas D. Willett*****
}

\begin{abstract}
We consider a domestic monopolist who is protected by an import quota on the product he produces. He faces a domestic demand curve which is characterized by a constant price elasticity. He is unable to export and has an upward sloping marginal cost curve. We demonstrate that in this case his employment of labor rises with the import quota until imports rise to a fraction 1/e of domestic output where $e$ is the elasticity of domestic demand. Thus, the employment maximizing quota sets permissible imports at a fraction of domestic output which is at least as high as the reciprocal of the elasticity of demand. We also make a case for liberalizing all the way right away, "cold turkey liberalization."
\end{abstract}

\section{INTRODUCTION}

The behavior of a monopolistic firm protected by a quota has received a great deal of attention by economists. This attention has almost universally focused on cases where the monopolist's marginal revenue curve is steeper than the demand curve as is the case with a linear demand curve.' However, such a relationship between average and marginal revenue does not always hold. In this paper, we explore the contrary case, where marginal revenue is flatter than demand--as it is with a constant elasticity of demand (CED) demand curve. Our results governing the behavior of the monopolistic firm under such a demand structure are in sharp contrast to typical findings.

Furthermore, as CED specifications are frequently used in empirical and computable general equilibrium studies, we believe our results are important. ${ }^{2}$

* Financial support from the Ford Foundation and the Walker Foundation of the Pittsburgh National Bank is gratefully acknowledged. The paper was written while Kaempfer and Tower were associated with the Economics Institute in Jakarta and revised while Tower was a Visiting Fellow at Australian National University. Thanks go to Jaehwa Lee, Barbara Spencer and Neil Vousden for helpful comments.

** Professor, Department of Economics, University of Colorado at Boulder, USA

*** Professor, Department of Economic, Duke University, Durham, USA

****Professor, Department of Economics, Claremont McKenna College \& Claremont Graduate University, USA

1 For examples see Gokcekus and Tower (1997), Hariharan and Wall (1992)and Kaempfer, Marks and Willett(1988).

2 Brander and Spencer (1984) address the importance of the convexity of domestic demand in the context of tariff policy in the presence of foreign private-sector monopoly power. Tower (1983) does the same in the presence of an optimizing foreign fiscal authority. Jones (1987) develops these ideas further. 
We prove the following theorem:

The employment maximizing quota: Consider a domestic monopolist who is protected by an import quota on the product he produces. He faces a domestic demand curve which is characterized by a constant price elasticity of demand which exceeds unity. He is unable to export and has an upward sloping marginal cost curve. In this case his employment of labor is an increasing function of the import quota, until permissible imports rise to a fraction, 1/e, of domestic output where $e$ is the elasticity of demand. Thus, the employment maximizing quota sets permissible imports at a fraction of domestic output which is at least as high as the reciprocal of the elasticity of demand.

After establishing this paradoxical result, the paper discusses how price and welfare depend on the quota. The $\mathrm{CED}$ assumption generates a marginal revenue curve which is flatter than demand. A linear demand curve generates a marginal revenue which is steeper. The paper is designed as a companion to Eldor and Levin (1990), which asks the same questions in the context of a marginal revenue curve which is steeper than the demand curve. ${ }^{3}$ Some radically different conclusions emerge.

\section{PROOF OF THE THEOREM}

Figure 1 illustrates the domestic market for widgets. $P$ is domestic price, $X$ is the domestic monopolist's production, $D$ is domestic quantity demanded, and

$$
D=X+M \text {, }
$$

where $M$ is imports. $C^{\prime}$ is the monopolist's marginal cost with vertical intercept, t3. It is upward sloping. The $I$ 's are isoprofit curves for the monopolist. As discussed in Kaempfer, Tower and Willett (1989), they have positive second derivatives and are flat where they intersect $C$ '.

The monopolist produces where one such curve is tangent to the excess demand for his widgets, $E=D-Q$, where $Q$ is the import quota. Under autarky, $E$ coincides with $D$. Thus, autarky equilibrium is at $a$, where $I_{0}$ is tangent to $D$.

We assume that $D$ exhibits a constant price elasticity of demand, e, which exceeds unity, so that the monopolist produces positive output, both in autarky and when protected with an import quota. We normalize price, so that

$$
D=P^{e} \text {. }
$$

3 They note (footnote 6), building on Ruffin (1971), that the condition for the marginal revenue curve faced by the monopolist to be steeper than the démand function is the same as the marginal revenue faced by the monopolist to be a diminishing function of the import, i.e. $P^{\prime}+P^{\prime \prime}<0$. Using the termonology of Bulow, Geanakopolos and Klemperer (1985), the two goods, domestic production and imports are strategic complements or substitutes depending on whether marginal revenue is an increasing or decreasing function of imports. 
Assume temporarily that the foreign price, $P^{*}$, is $f_{3}$, the vertical intercept of the flat supply curve, $F_{3}$, where $f_{3}<t_{3}$. Thus imports equal $Q$ so long as $P$ exceeds $f_{3}$. As the import quota rises, $E$ shifts leftward.

The monopolist's output rises (or falls) depending on whether his marginal revenue curve, $R^{\prime}$ (not shown), shifts up (or down).

Now we ask, "Which way does $R$ ' shift?" This may seem to be a stupid question, for we can quickly see that with a linear demand curve, an increased import quota will always shift $R^{\prime}$ to the left. But with a CED curve, that is never the case. For example, suppose (contrary to the assumption made in the rest of the paper) that $D$ has an elasticity equal to 1 . Then $R^{\prime}=0$. A jump in the import quota from zero to $I$ unit, causes a unitary shift of $E$ to the left. At any price, the slope of $E$ is the same as before; $P$ is unchanged; $X$ is one unit smaller. This means that the elasticity of $E$, $[d X / d P] /[X / P]$, is higher. Since $R^{\prime}=P\{1-(1 / e)\}, R^{\prime}$ is now everywhere positive. Thus, $R^{\prime}$ has shifted upward throughout its entire range.

Now we explore how imports shift $R^{\prime}$ in the general ced case.

Combining (1) and (2) yields:

$$
X+M=P^{e}
$$

The monopoly's revenue is

$$
R=P X,
$$

so from (3) and (4)

$$
R=X[X+M]^{-1 / e}
$$

Differentiating with respect to $X$,

$$
R^{\prime}=[X+M]^{1 / e}-\left[X+M-1^{1 \cdot 1 / e} X / e\right.
$$

Totally differentiating gives:

$$
d R^{\prime}=\frac{[X-e M] d M-[(e-1) X+2 e M] d X}{e^{2}[X+M]^{2+1 / e}}
$$

Since $e>1, d R^{\prime} / d M$ is positive if and only if $M<X / e$, i.e. if and only if imports are less than output divided by the demand elasticity. (7) also tells us that $d R^{\prime} / d X$ is negative. Consequently, as the import quota is relaxed $X$ will rise until imports reach the critical proportion of output, and then fall.

Is it possible that $X$ falls so rapidly with additional imports that $P$ rises? $X$ falls most rapidly when $C^{\prime}$ is flat. In that case $d R^{\prime}=d C^{\prime}=0$. Plugging this relationship into (7) yields:

$$
\frac{d X}{d M}=\frac{X-e M}{X(e-1)+2 e M}
$$

if $C^{\prime}$ is flat. This ratio is minimized when $X / M \rightarrow 0$. The minimum value for this ratio is $-1 / 2$. Thus increased imports must always increase $D=X+M$ and shrink $P$. This allows us to trace various scenarios in Figure 1. 
Figure 1. Price-Output Trajectories

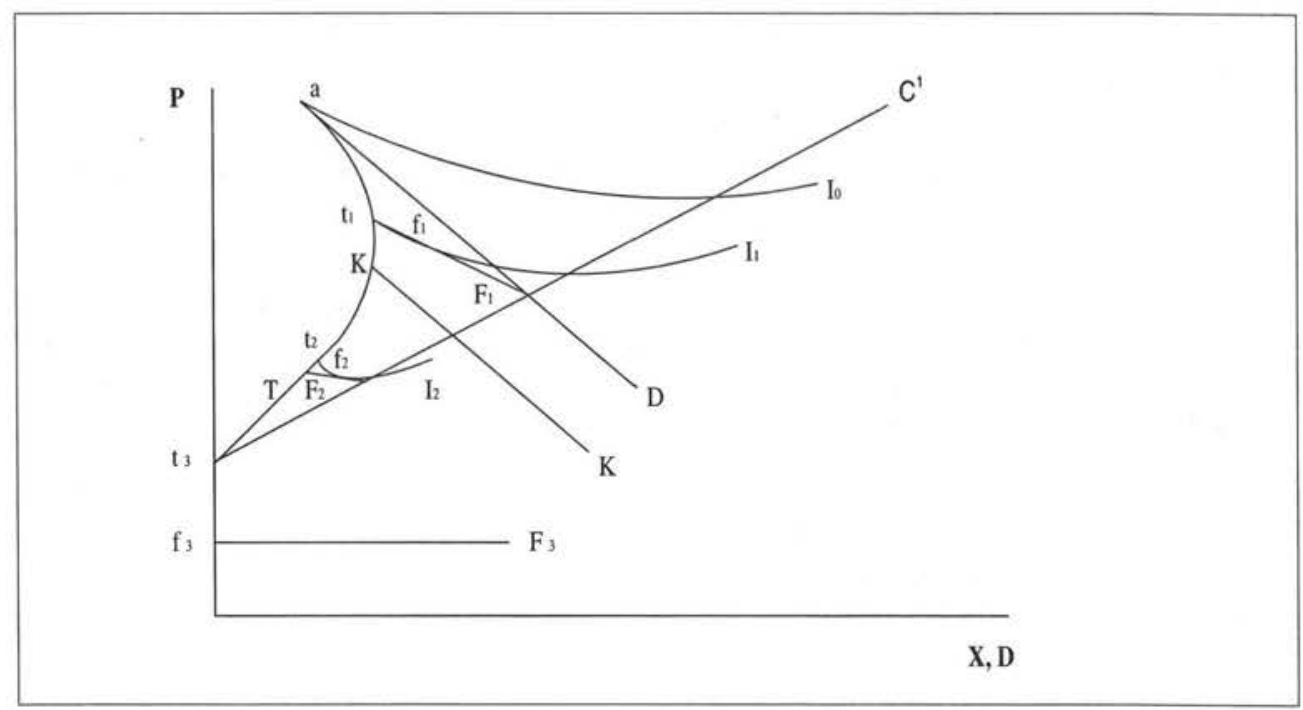

$K$ is the locus of $(P, X)$ where the ratio of $M$ to $X$ equals that critical value: $1 / e$. It is given by $D e /(1+e)$, which is $D$ shifted leftward by a fraction, $1 /(1+e)$. It shows the locus where the ratio of $M$ to $X$ equals that critical value: $1 / e$. As the quota, $Q$, expands from zero to cover the whole domestic market, $(P, X)$ takes the path $\mathrm{akt}_{3} \mathrm{f}_{3}$, along trajectory, $T$. This path shows $X$ rising monotonically until imports reach the critical level at $k$, the intersection between $K$ and $T$ and falling monotonically thereafter, to zero when $P=t_{3}$, the vertical intercept of $C^{\prime}$. Now we relax the assumption that $P^{*}$ equals $f_{3}$.

Suppose we relax the small country assumption and allow for an upward sloping foreign excess supply curve. The free trade excess demand curve facing the monopoly becomes either like $F_{1}$ (which intersects $T$ above $k$ ), or like $F_{2}$ (which intersects $T$ below $k$ ). $f_{i}$ and $\mathrm{f}_{2}$ show the tangencies between isoprofit contours and $F_{l}$ and $F_{2}$ respectively. $t_{1}$ and $t_{2}$ show the intersections between these same isoprofit contours and $T$. Once the quota becomes slightly more liberal than that at $t_{1}$ or $t_{2}$, assuming the monopolist faces an excess supply of $F_{1}$ or $F_{2}$ he maximizes profits where he produces enough (at $f_{1}$ or $f_{2}$ ) to make the quota redundant, so an infinitesimal liberalization causes output to jump.

Figure 2 illustrates the same story as Figure 1, except in $(X, Q)$ space. With $F_{l}, X$ rises with the import quota along at ${ }_{1}$ and then jumps up to $f_{l}$, where $P$ falls to $P^{*}, M$ falls and $Q$ is nonbinding (Figure 2's curve $T_{l}$ ). With $F_{2}, X$ rises and then falls with the import quota along $a t_{2}$ and then jumps up to $f_{2}$, where, again, $P$ falls to $P^{*}, M$ falls, and $Q$ is nonbinding (Figure 2's curve $T_{2}$ ), and $X\left(f_{2}\right) \gtrless X(a)$. With $F_{3}$, X rises and falls as $(P, X)$ follows $a t_{3} f_{3}$, until imports wipe out domestic production (Figure 2 's curve $\left.T_{3}\right)$. 
Figure 2. How Output Depends on the import Quota

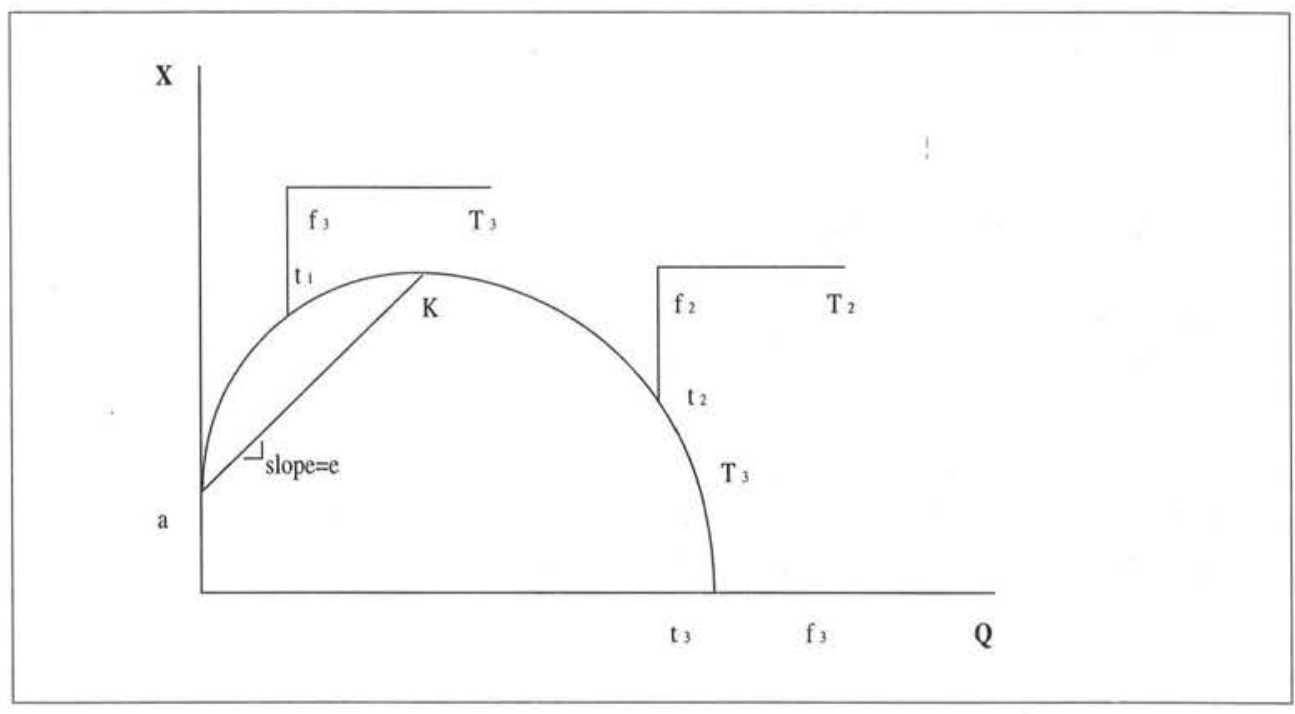

This concludes the proof of the theorem. The analysis implies that to maximize employment, the import quota should always be increased at least until imports equal $1 / e$ times domestic output. Notice, however, that as the import quota is relaxed, the excess demand curve shifts left and profits monotonically fall.

\section{WELFARE}

The welfare implications of liberalization are more complex. This section examines welfare changes $(d W)$ under the alternative assumptions of quota auctions which redistribute all quota rents as non-distorting lump sums or total rent dissipation to foreigners or rent seekers. We also look at the cases where domestic marginal cost is downward sloping (rather than upward sloping) and where output makes discrete jumps in response to marginal quota liberalization to a non-binding quota.

Define $h$ as an indicator variable which takes on a value of $l$ when the social value of quota rents accrue to the home country. When import licenses are auctioned off, so quota rents go to the home government or else if the import licenses are distributed to home residents and there is no rent seeking behavior we set

$$
h=1 \text {. }
$$

For simplicity, we refer to both cases as "the auctioned import quota."

There are two reasons why quota rents have no social value to the home country.

When "voluntary export restraints" are imposed on foreigners, they receive the quota rents. When home residents receive the import licenses but they exhaust the rents in rent seeking behavior, the rents are competed away. We refer to both cases as "rent dissipation," since the home country gets no benefit from the quota rents. In these cases, 


$$
h=0 .
$$

We define welfare change as the sum of the changes in consumer surplus, monopoly profits, and non-dissipated quota rents:

$$
d W=-[X+M] d P+\left(X d P+\left[P-C^{\prime}\right] d X\right)+h d\left[M\left(P-P^{*}\right)\right] .
$$

\section{Welfare with rent dissipation}

Suppose the quota rent is dissipated. In that case,

Combining (10) and (11):

$$
d W=\left[P-C^{\prime}\right] d X-M d P,
$$

which tells us that in the range where $X$ is rising, $W$ also rises with $M$.

In the range where $\mathrm{X}$ is falling, we take the case where $W$ is most likely to decline, namely where $C^{\prime}$ is flat. Differentiating (3) yields

$$
d P=-P^{e+1} \frac{d M+D X}{e} .
$$

The elasticity of the excess demand curve is

$$
e^{\prime}=\frac{e[M+X]}{X} .
$$

The well-known formula for marginal revenue is

$$
R^{\prime}=P\left[1-\frac{1}{e^{\prime}}\right] \text {. }
$$

The monopolist equates marginal revenue to marginal cost:

$$
R^{\prime}=C^{\prime} .
$$

Substituting (16) into (15) to eliminate $R^{\prime}$, and (14) into the result to eliminate $e^{\prime}$ yields

$$
P-C^{\prime}=\frac{P X}{e[M+X]} .
$$

Substituting (13) and (17) into (12) to eliminate $d P=P-C^{\prime}$, then substituting (8) into the result to eliminate $d X / d M$, then substituting (3) into that result to eliminate $P^{e}$ yields:

$$
\frac{d W}{d M}=\frac{P\left[e M^{2}+X^{2}\right]}{e[M+X][(e-1) X+2 e M]} .
$$

which is necessarily positive. Thus even in the range where $X$ is falling $W$ is necessarily rising.

To conclude, with rent dissipation, output is maximized where the import quota is at least as high as domestic output divided by the elasticity of domestic demand, and welfare rises monotonically with the import quota. 


\section{Welfare with an auctioned import quota}

With the auctioned quota, $h=1$, so (11) can be rewritten as the sum of the flow of goods across distortions minus the change in rents accruing to foreign suppliers:

$$
d W=\left[P-P^{*}\right] d M+\left[P-C^{\prime}\right] d X-M d P^{*} .
$$

Welfare may decline with quota increases as soon as imports become large enough for the terms-of-trade effect to weigh significantly. Consider the special case of a vertical $C^{\prime}$ which freezes monopoly output.

Now, welfare is maximized at the quota which replicates the price differential which would be generated by the orthodox optimum tariff. This may occur even when imports are less than domestic output divided by the elasticity of domestic demand. However, if the orthodox optimum import tariff (i.e. that tariff which just internalizes the externality due to the terms of trade effect), is imposed on top of the import quota, welfare will rise with quota liberalization so long as domestic output rises as well.

As a special case, if we invoke the small country assumption, i.e. assume that world price is fixed, then in the range where $X$ increases, $W$ also necessarily increases. But in the range where $X$ decreases $W$ may fall, even when $P^{*}$ is fixed. If $P$ is close to $P^{*}$, the first term of (19) will be close to zero, and the expression will be dominated by the negative second term. The problem here is that the low-social-cost monopoly output is being squeezed by higher priced imports. Still, even in this case, free trade will be the welfare maximizing equilibrium, with the home price falling to the fixed world price.

This special case illustrates what we label policy point \#1:

The case for liberalizing all the way right away: An incremental quota liberation may simultaneously reduce employment and welfare. For a small country, complete liberalization maximizes welfare and may maximize employment. When it does maximize both it is best from the standpoint of both employment in the industry and welfare to liberalize immediately and completely.

\section{Downward sloping marginal cost}

Economies of scale account for the existence of many monopolies. Thus it is reasonable to assume that the monopolist' s marginal cost curve is downward sloping. In that case, as imports rise, even though $R^{\prime}$ is shifting upward, the monopolist' $\mathrm{s}$ profits may be forced to zero even before the import/output ratio reaches its critical level. Thus, $X$ reaches a peak at the critical import/output ratio or the zero profit level of imports, whichever comes first.

Moreover, with either rent dissipation or the auctioned quota, if the downwardsloping marginal cost schedule is almost as steep as $R^{\prime}$, then import expansion may cause a marked decline in domestic output, raising $P$ and reducing welfare. If we further postulate the small country assumption, then free trade is the best policy. Thus, even with rent dissipation, incremental liberalization may immiserize, while complete liberalization maximizes welfare. 


\section{Welfare when output jumps}

Suppose that incremental quota relaxation causes output to jump discretely as in the cases of $f_{i}$ and $f_{2}$ in the Figures. These jumps cause domestic price to fall to world price, so the import quota becomes non-binding. Because of the non-continuous nature of these adjustments, equation (11) with $h=1$ must be integrated to yield a welfare change:

(20) Change in $W$ with the auctioned quota = Foreign exchange saved $(A)$ - Extra domestic production cost $(B)+$ Area under the demand curve between the initial and final consumption levels $(C)$.

For the monopolist to find the extra production profitable it must

be true that

(21) [Final price]*[extra production] $(D)$ - Extra domestic production $\operatorname{cost}(B)>0$. regardless of the shape of $C^{\prime}$.

Since $C>D$ and $A>0$, the right hand side of $(20)>$ the left hand side of $(21)>0$. Thus, the change in $W>0$. Consequently, whenever there is a jump in output, regardless of the slope of $C^{\prime}$, welfare must rise.

Rents fall, so with rent dissipation, the welfare gain is even larger. Thus welfare rises under both quota schemes.

\section{Summary}

All these results are summarized in Table 1.

Table 1. Effects of Quota Liberalization on Output, Price and Welfare

\begin{tabular}{|c|c|c|c|}
\hline \multirow{5}{*}{$\begin{array}{l}\text { Regard-less } \\
\text { of } \\
\text { slope } \\
\text { of } C^{\prime}\end{array}$} & $d M / d Q<0$ & \multicolumn{2}{|l|}{ If $\pi-\pi(N B Q)=0^{+}$} \\
\hline & $d X / d Q<0$ & \multicolumn{2}{|c|}{ If $Q>X / e$ unless $\pi-\pi(N B Q)=0$. } \\
\hline & \multirow{2}{*}{$d X / d Q \geq 0 ; d P / d Q \leq 0$} & \multicolumn{2}{|c|}{ If $Q<X / e \& \pi>0^{+}$} \\
\hline & & \multicolumn{2}{|c|}{ If $\pi-\pi(N B Q)=0^{+}$} \\
\hline & $d W / d Q \geq 0$ & \multicolumn{2}{|c|}{ If $d X / d Q \geq 0$ \& either OT or RD } \\
\hline \multirow{6}{*}{$\begin{array}{l}C^{\prime} \\
\text { flat or } \\
\text { upward } \\
\text { sloping }\end{array}$} & \multirow{2}{*}{$d X / d Q \geq 0$} & \multicolumn{2}{|c|}{ If $Q<X / e$} \\
\hline & & \multicolumn{2}{|l|}{ If $\pi-\pi(N B Q)=0^{+}$} \\
\hline & \multicolumn{3}{|l|}{$d P / d Q \leq 0$} \\
\hline & $R D$ & $d W / d Q \geq 0$ & \\
\hline & \multirow[t]{2}{*}{$Q A$} & Always $d W / d Q \geq 0$ & If $d X / d Q \geq 0 \& O T$ \\
\hline & & $\begin{array}{l}\text { possibly } \\
d W / d Q<0\end{array}$ & $\begin{array}{l}\text { If } T O T E \text { is strong \& } \\
\text { No } O T \text {, or } d X / d Q<0\end{array}$ \\
\hline \multirow[t]{3}{*}{$\begin{array}{l}C^{\prime} \\
\text { down-ward } \\
\text { sloping }\end{array}$} & \multirow[t]{2}{*}{$\begin{array}{l}d X / d Q<0 \\
d P / d Q<0 \\
d W / d Q<0\end{array}$} & \multicolumn{2}{|l|}{ If $\pi=0^{+}$} \\
\hline & & \multicolumn{2}{|c|}{$\begin{array}{l}\text { If } C^{\prime} \text { is almost as steep as } R^{\prime} \& \\
Q>X / e \text { unless } \pi-\pi(N B Q)=0^{+}\end{array}$} \\
\hline & Possibly $d W / d Q<0$ & \multicolumn{2}{|c|}{ Under $A Q$ if TOTE is strong \& No $O T$ even if $d X / d Q>0$} \\
\hline
\end{tabular}




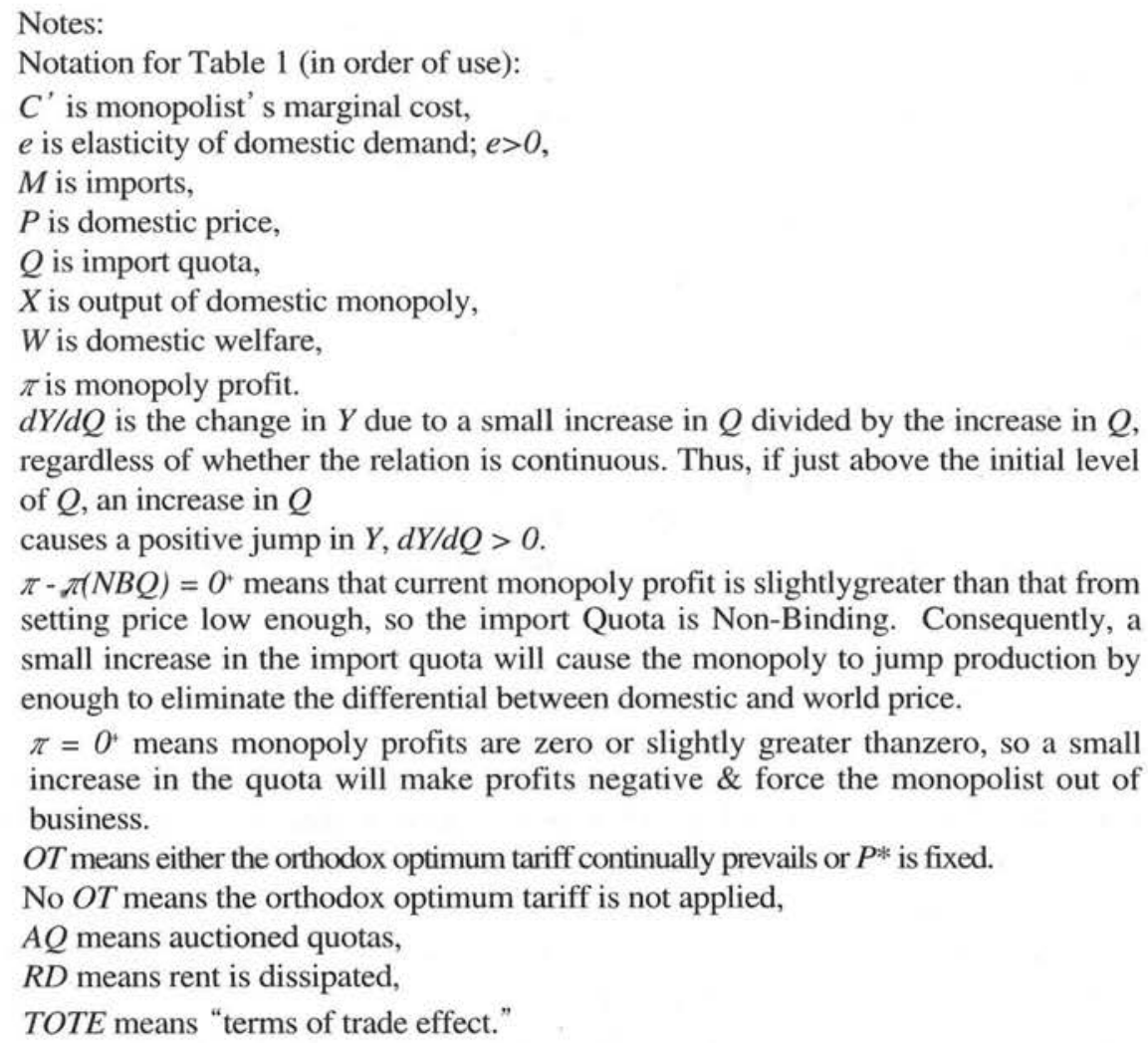

\section{COMPARISON WITH ELDOR-LEVIN}

Eldor and Levin (1990) analyzed the same problems under the same assumptions except they assumed that marginal revenue is steeper than demand. In their models both with the VER (what we call rent dissipation) and the auctioned quota it is possible for an incremental liberalization to reduce both welfare and output while complete liberalization raises both above autarky levels, although they do not focus on the non-monotonicity of output. Thus on both grounds their model in some cases provides a case for immediate and complete liberalization. It is important to note that in their model if marginal cost lies uniformly below world price, at some quota, as discussed in Kaempfer, McClure and Willett (1989), output and imports are both indeterminate, so at some point in the liberalization, output makes a positive jump from a situation with a binding quota to a non-binding quota, while imports make a negative jump. Thus, it is important to distinguish between the size of the quota and the level of imports.

Let us now examine EL's Proposition 2 which states "restricting the 'last unit' of import of entering the country by VER unambiguously reduces welfare." Their logic is that at free trade the monopolist sets marginal cost to price. So the change in welfare is given by the second term in our (12), which is necessarily negative. 
Suppose the foreign country only produces and exports a tiny amount of the good, the home monopolist has economies of scale, and under free trade he is barely unable to cover costs. Introducing a VER which keeps out the last unit makes domestic production profitable for him, increases domestic output to a finite level from zero, shrinks domestic price, improves the terms of trade (because the foreigner must sell at the new lower domestic price), and raises welfare. Stated more formally, our point is: starting from autarky, for any proposed VER no matter how small, there exists some domestic cost structure which causes the proposal to be welfare enhancing.

\section{EL's Proposition 3 states:}

Assume a monopoly in the domestic importing industry of a small country and import restriction in the form of quota licenses which are auctioned off. If (A1) [marginal revenue is steeper than demand] and (A2) [the algebraic value of the slope of the marginal cost curve is greater than that of the demand curve] hold and the domestic marginal cost is greater [than] or equal to the foreign commodity price, any increase in import increases welfare until free trade...

Their logic is that the monopolist' s output falls more slowly than imports rise, resulting in steadily falling domestic price and steadily rising domestic welfare. It is possible to produce a counterexample. Suppose marginal cost is downward sloping. At some point increased imports may cause the domestic monopolist's profits to fall to zero, forcing him out of business, resulting in lost welfare. However, if the monopolist's marginal cost is uniformly non-negatively sloped than the theorem holds.

Table 2 compares some of the results derived in the present paper (KTW) with those of EL.

Table 2. Comparing the Results of KTW with those of EL

\begin{tabular}{|c|c|c|c|}
\hline & EL result & \multicolumn{2}{|c|}{ KTW result } \\
\hline \multirow[t]{2}{*}{$\begin{array}{l}\text { With } A Q \text { for a small country } \\
\text { W increases with } Q\end{array}$} & \multirow[t]{2}{*}{$\begin{array}{l}\text { if } C^{\prime}>P^{*} \\
{\left[\& \pi>O^{+} \gamma^{4}\right.}\end{array}$} & \multicolumn{2}{|c|}{ if $Q<X / e \& \pi>0$} \\
\hline & & \multicolumn{2}{|c|}{ if $\pi-\pi(N B Q)=0^{*}$} \\
\hline With $R D$ the first unit of $M$ & decreases $W$ & raises $W$ & $\begin{array}{l}\text { unless } C^{\prime \prime}<0 \& \text { almost } \\
\text { as steep as } R^{\prime} \text { or } \\
\text { both } C^{\prime \prime}<0 \& \pi=0^{+}\end{array}$ \\
\hline With $A Q$ the first unit of $M$ & necessarily reduces $W$ if $C^{\prime}<<P^{*}$ & raises $W$ & $\begin{array}{l}\text { if } C^{\prime \prime} \geq 0 \text { or } \\
\pi>0^{+}\end{array}$ \\
\hline $\begin{array}{l}\text { With } R D \& C^{\prime}=P^{*} \\
=\text { constant }\end{array}$ & $\begin{array}{l}\text { with a linear demand curve } W \text { is a } \\
\text { single troughed function of } Q \text { at } \\
M=4 X, \& X \text { falls monotonically } \\
\text { [being indeterminate at free trade] }\end{array}$ & \multicolumn{2}{|c|}{$\begin{array}{l}W \text { monotonically rises; } X \text { is single } \\
\text { peaked with peak at } M=X / e \text {, except } \\
\text { it is indeterminate at free trade }\end{array}$} \\
\hline
\end{tabular}

4 The qualifier in the brackets is necessary and has been added by the current authors. For further explanation, see notes to Table 1. EL and $K T W$ make identical assumptions except that $E L$ assumes $R$ ' is steeper than the demand curve which generates it, whereas $K T W$ assumes a constant elasticity of domestic demand so $R$ ' is flatter than demand. 
A striking contrast emerges between a situation where marginal revenue is steeper than demand, e.g. the linear demand curve, and the CED case analyzed in this paper. When marginal revenue is steeper than demand, the first unit of liberalization always reduces output and employment; with rent dissipation it always reduces welfare (because the welfare change equals $\left[P-C^{\prime}\right] d X$ ), while with the auctioned quota welfare may rise or fall. In the ced case, by contrast, output, employment and welfare always rise, except in the extreme case where the first unit of liberalization forces the monopolist out of business. Finally it is easy to show that any finite increase in imports has the same or a smaller negative effect on monopoly rents, and hence (if $C$ " $<0$ ) a smaller probability of the monopoly going out of business, with the ced curve than with the linear one, given identical foreign supply and domestic cost functions, and identical prices and quantities. ${ }^{5}$ Thus, the case for a small amount of liberalization, starting from autarky, on the grounds of trading off these considerations is better with the CED curve than with the linear one.

\section{THE CASE FOR LIBERALIZATION IMPROVES AS THE CONVEXITY OF THE DEMAND CURVE INCREASES}

The analysis in the preceding section suggests the hypothesis that the case for liberalization becomes stronger the more convex the demand curve is. Let us see if this is true.

Let the demand curve be

$$
P=P(M+X) \text {. }
$$

Revenue is

$$
R=X P(M+X)
$$

Marginal revenue is

$$
R^{\prime}=P(M+X)+X P^{\prime}
$$

Marginal cost, $C^{\prime}$ intersects $R^{\prime}$ from below, so

$$
C^{\prime}{ }_{x}-R^{\prime}>0 \text {. }
$$

Setting $R^{\prime}=C^{\prime}$ and totally differentiating this equilibrium condition gives

$$
\frac{d X}{d M}=\frac{R_{M}^{\prime}}{C_{x}-R_{x}^{\prime}} .
$$

Using the partial derivatives of (24) to evaluate (26) yields

$$
\frac{d X}{d M}=\frac{P^{\prime}+X P^{\prime \prime}}{C_{x}^{\prime}-2 P^{\prime}-X P^{\prime \prime}} \text {. }
$$

5 The proof is as follows. Denote $E\left(M_{i}\right)$ as $E$. From any initial level of imports, $M_{0}$, and price, $P_{i}$, introduce additional imports, so the new import level is $M_{l}$. This causes $E_{l}$ to be $D$ shifted to the left by $M_{l}$. Suppose $D$ is linear. Note the tangency of $E_{0}=D-M_{0}$ with one of the isoprofit lines. This is the initial equilibrium with the linear $D$. With a CED $D, E_{f}$ will be tangent to the linear $E_{l}$ at $P_{o}$ and at other prices will lie uniformly to the right of the linear $E_{l}$. Thus, somewhere, the $C E D E_{i}$ must touch a higher isoprofit contour than the linear $E_{i}$ does. 
Differentiating (27) with respect to $P$ ", and substituting the denominator of the right hand side of (26) for that of (27) yields

$$
\frac{d\left[\frac{d X}{d M}\right]}{d P^{\prime \prime}}=\frac{X\left[C_{x}^{\prime}-P^{\prime}\right]}{\left[C_{x}^{\prime}-R_{x}^{\prime}\right]^{2}}>0 .
$$

Let us adopt EL's assumption A2, i.e. that the numerator of (28) is positive. This is assured by stability if marginal revenue is flatter than demand or marginal cost is not downward sloping. Thus, given $\mathrm{A} 2, C, P, P^{\prime}, M$ and $X, d X / d M$ will be more positive the greater is $P$ ", i.e. the more convex is demand. Now consider an incremental increase in $M$. At constant $X$, the change in price, monopoly profit and welfare will be independent of $P^{\prime \prime}$. Since $X$ is continually adjusted to maximize monopoly profits, the envelope theorem tells us that $d n / d X=0$, so even with $X$ variable, the change in monopoly profit is independent of small changes in $X$ and hence independent of $P^{\prime \prime}$. Price decreases with $X$ and welfare rises with $X$.

Consequently, a policymaker whose utility depends positively on welfare, monopoly output, monopoly employment, negatively on price and positively or negatively on monopoly profit, will find additional liberalization more desirable the more convex the demand curve is, given A2, imports, the foreign supply function, domestic price and quantity and the domestic cost curve. This gives us what we label as policy point \#2:

Beware of using the linear case as a benchmark: Policy makers should be wary of using the simple linear case as a benchmark for cost-benefit analyses of liberalization when demand curves are likely to be more convex than the linear case as it understates the appeal of liberalization.

\section{POLICY IMPLICATIONS: AVOID PROHIBITIVE IMPORT QUOTAS AND GIVE LABOR A SAY IN DETERMINING IMPORT QUOTA LEVELS}

It is well known that gradually lowering an import tariff may cause a monopolist to gradually expand output. EL note that gradually liberalizing an import quota may do the same, as increased imports may shift marginal revenue upwards, although EL have not followed up this point to the degree that they have looked at welfare. We have demonstrated that for a CED domestic demand curve and an upward sloping marginal cost curve, this result necessarily obtains until imports reach a critical value equal to domestic output divided by the elasticity of domestic demand. Thus, to maximize employment when the monopoly is confronted by a domestic CED demand curve, the import quota should be set at least as high as the monopolist' $\mathrm{s}$ output times the reciprocal of the elasticity of domestic demand.

However, profit is maximized with a zero quota. Thus assuming monopoly rents are not captured by labor, political systems in which a sector's labor is given a strong voice relative to the sector's capital in determining import quotas should generate larger import quotas. 
We also found that even in the small country case, both welfare and employment may decline with an incremental liberalization starting from a position of some trade, whereas both rise to a maximum with free trade. When this happens, "cold turkey liberalization" is desirable on both scores. ${ }^{6}$

\section{REFERENCES}

Brander, J.A. and B.J. Spencer (1984) “Trade Warfare: Tariffs and Cartels," Journal of International Economics 16, 227-242.

Bulow, J.I., J.D. Geanakopolos and P.D. Klemperer (1985) "Multimarket Oligopoly: Strategic Substitutes and Complements," Journal of Political Economy 93, 488511.

Eldor, R. and D. Levin (1990) "Trade Liberalization and Imperfect Competition: A Welfare Analysis," International Economic Review 31, 773-781.

Gokcekus, O and E. Tower (1997) "Can a Periodic Voluntary Export Restraint Raise Importing Country Welfare?” Journal of Economic Integration, 12, 485-504.

Hariraran, G. and H.J. Wall (1992) "Intertemporal Optimization under Threat of VER," Review of International Economics 7, 45-57.

Jones, R.W. (1987) "Trade Taxes and Subsidies with Imperfect Competition," Economics Letters 23, 375-379.

Kaempfer, W. H., J. H. McClure, Jr. and T. D. Willett (1989) "Incremental Protection and Efficient Political Choice Between Tariffs and Quotas," Canadian Journal of Economics 22, 228-236.

Kaempfer, William H., Edward Tower and Thomas D. Willett (1989) "PerformanceContingent Protection “Economics and Politics, 261-275.

Ruffin, R. J. (1971) "Cournot Oligopoly and Competitive Behavior," Review of Economic Studies 38, 493-502.

Tower, E. (1983) "Making the Best Use of Trade Restrictions in the Presence of Foreign Market Power," Journal of International Economics 15, 456-473.

\footnotetext{
- Complete, unanticipated liberalization is sometimes referred to as "cold turkey" liberalization. The term refers to the goosebumps suffered by an addict who is withdrawn suddenly from heroin. But in this case, complete liberalization may raise both employment and welfare, with labor suffering not at all. Such liberalization should produce goosebumps only for those who are initially receiving monopoly or quota rents generated by the trade restriction.
} 